УдК 316.621:316.648.43:327

\title{
ЮВЕНАЛЬНЫЕ ФОБИИ ПОСТАПОКАЛИПТИЧЕСКОЙ ВЛАСТИ: МОРАЛЬНАЯ ДЕВОЛЮЦИЯ ЛИЧНОСТИ В ЖЕРНОВАХ БИОПОЛИТИКИ
}

\author{
Маленко Сергей Анатольевич, \\ olenia@mail.ru \\ Некита Андрей Григорьевич, \\ beresten@mail.ru
}

Новгородский государственный университет имени Ярослава Мудрого, Россия, 173003, Великий Новгород, ул. Большая Санкт-Петербургская, 41

\begin{abstract}
Маленко Сергей Анатольевич, доктор философских наук, профессор, заведующий кафедрой философии, культурологии и социологии Новгородского государственного университета имени Ярослава Мудрого.
\end{abstract}

Некита Андрей Григорьевич, доктор философских наук, профессор кафедры философии, культурологии и социологии Новгородского государственного университета имени Ярослава Мудрого.

Актуальность. Антропологический кризис, в который ввергнута современная цивилизация, задает новые стандарты интерпретации противоречий между поколениями и диктует сценарии их визуализации. Данный конфликт приобретает политико-идеологическое звучание, что требует гуманитарной экспертизы этой ситуации и формирования корпуса рекомендаций по минимизации негативных последствий. Цель: на примере голливудской франшизы о «Дивергенте» проанализировать стратегии формирования постапокалиптического социального пространства и принципы деформации межпоколенческой коммуникации. Методы: авторы опираются на междисциплинарный комплекс семиотического, феноменологического и психоаналитического методов, позволяющий всесторонне проанализировать биополитические и идеологические стратегии постапокалиптической власти. Результаты: укрепление институтов власти будущего осуществляется посредством насаждения тоталитарной, иерархической системы, каждый уровень которой выполняет предписанную моральную миссию, что позволяет придавать ее официальным и повседневным функциям высшие сакральные и антропологические смыслы. Эффективность существования фракционной системы постапокалиптического будущего обеспечивается за счет создания жесткого механизма социализации, призванного формировать и канонизировать стандартизированные моральные добродетели. Функционированию подобного отлаженного механизма препятствуют дивергенты - индивиды, обладающие всеми фракционными способностями одновременно. Их универсальность подрывает стабильность антиутопического социума, что обуславливает стремление власти к физическому устранению дивергентов из социального пространства. Государственному порядку противопоставлена внесистемная оппозиция инсургентов - девиантов, стремящихся уничтожить фракционную детерминацию. Демонстративная борьба фракционного социума с инсургентами является его системной функцией, укрепляющей позиции власти, которая выступает закономерным результатом теневых экспериментов над обществом. Выводы: использование технологий профессиональной сегрегации становится ведущей биополитической, коммунитарной стратегией постапокалиптической тоталитарной власти.

Ключевые слова: Постапокалипсис, дивергент, инсургент, аллигент, биополитика.

Распад Советского Союза с последующим уничтожением социалистического лагеря фактически предрешил крушение системы биполярного мира, которая последовательно осуществляла трансляцию ключевых социоформирующих смыслов, надежно обеспечивавших функционирование более или менее сбалансированного пространства 
циркуляции ценностных установок и мировоззренческих идеалов во всем мире. Однако ранее, на протяжении предшествующих десятилетий, ключевые социальные идеалы формировались и апробировались в результате напряженного политического, экономического, идеологического и социокультурного соперничества властей большинства стран за умы и души людей. В сложившихся условиях обыватели в разных районах мира всерьез столкнулись с отсутствием каких бы то ни было объединяющих идеалов, при том, что потребность в их наличии не только не исчезла, но и наоборот - в значительной мере обострилась на фоне возрастающих военных, политических, экономических и экологических проблем, непосредственно угрожающих как каждому отдельному человеку, тем или иным социальным группам, странам и народам, так и всему человечеству.

Парадокс ситуации состоит в том, что хотя подобные глобальные противоречия и находятся все время в поле зрения ведущих политиков мира, но тем не менее от этого они не только не решаются, но год от года лишь усугубляются, в то время как современная визуальная культура и ее кинематографические «кудесники» в лице голливудских режиссеров и продюсеров целенаправленно и настойчиво посвящают себя поиску актуальных ответов на эти вызовы времени. Ошеломляющий и крайне парадоксальный успех киножанра постапокалипсиса «как своего рода мягкой силы» [1, p. 385], безусловно, свидетельствует о насущной необходимости переосмысления действующей палитры социальных идеалов, позволяющих обозначить не только стратегические цели и сиюминутные потребности, но и сформулировать более или менее внятные мотивы и сценарии их достижения.

И, конечно, в деле решения столь сложной и многоаспектной задачи достаточно закономерным выглядит обращение Голливуда (как элитного пространства «хорошо выглядящих или старающихся хорошо выглядеть загорелых, наглаженных, наманикюренных перепуганных людей» [2, с. 199]) к проблемам, рефлексией над которыми традиционно, на протяжении десятков веков, занимались лишь религии и утопии. Действительно, с начала XX в. к их обсуждению подключились ещё и антиутопии, что не только превратило мировую «фабрику грез» в альтернативный политическому, крайне эффективный инструмент поиска сценариев преодоления социальных конфликтов, но и обеспечило именно ей приоритет в формировании и популяризации прорывных проектов коммуникации будущего. Особенно эта тема стала популярной в последние два десятилетия нового века, парадоксальным образом превратившись в топовый «развлекательный» сюжет для разочаровавшегося во всем и вся современного массового человека, который внезапно увидел и почувствовал, что практически все голливудские киноленты в той или иной мере «непременно имели политический окрас» [3, с. 126].

Ещё одним парадоксом XXI в., выраженным в повсеместно повторяющихся сюжетах, связанных с кошмарным будущим человечества, стал трагический, непрерывно усугубляющийся конфликт поколений, разворачивающийся в контексте непременной тоталитаризации власти, которая изо всех сил пытается сохранить, а местами даже и усилить свой медийный, псевдодемократический профиль. И если для классической европейской культуры Нового времени конфликт поколений имел исключительно бытовой и «интериорный» характер, как правило, не выходящий за рамки одной семьи, то в миллениальных моделях коммуникации властный контекст подобных конфронтаций все более приобретает самодовлеющую ценность, напрочь вытесняя из него в первую очередь старшее поколение с его жизненным опытом, а также с присущими «отцам и дедам» навыками осмысления, переживания и реакции. И действительно, в голливудских постапокалиптических сюжетах миссия «поколения отцов» выражена крайне вяло, невыразительно и явно имеет как минимум второстепенную социализирующую и социокультурную роль. 
Классический конфликт поколений теперь разворачивается исключительно между молодежью и властью, занявшей все доступное физическое и экзистенциальное пространство. Таким образом, именно власть в постапокалиптическом мире окончательно отождествила и заместила своим управленческим опытом вообще весь поколенческий опыт. В итоге детям и молодёжи поколения «отцов» «не могут помочь решить их самые насущные проблемы» [4, р. 169], ведь они оказались полностью дискредитированными, поскольку традиционно взаимодействовали с поколениями «сыновей» на уровне межличностной коммуникации, пытаясь передать им ценные жизненные знания в наиболее доступной и неотчужденной форме. Тогда как «поколение отцов» могло сохраниться только при условии своего максимального соответствия институциональным практикам современной власти, т. е. оно должно было транслировать «детям» модель социального управления как единственно возможную форму лояльной социальной коммуникации и процедуру «закрепления моральных уроков для населения, которое оказалось отвлеченным от традиционных американских ценностей» [5, p. 243].

Именно в такой форме в постапокалипсисе и осуществлялась пропедевтика будущей коммуникации молодёжи с властью, в рамках которой старшее поколение оказывало власти лишь сервильные услуги по адаптации молодёжи к текущему формату властной коммуникации. Поэтому в абсолютном большинстве голливудских постапокалиптических сюжетов старшее поколение преимущественно изображается почти полностью утратившим свою социальную роль и выступающим лишь в качестве социального балласта как для власти, так и для всего общества. Как раз в силу этого именно разруха, повальная и хроническая нищета становятся главными отличительными признаками обществ будущего, в которых транслируется новая модель «общественного договора». В итоге именно деморализованное и полностью дискредитированное поколение «отцов» превратилось в тот необходимый промежуточный этап в оформлении тоталитарной власти как единственный транскультурный, а потому и сакральный символ, который отныне получил неограниченные полномочия, карт-бланш в отношении как социального, так и природного пространства постапокалиптического человечества. Следует с сожалением констатировать, что именно властное уничижение поколения «отцов» является закономерным и необходимым этапом для утверждения безраздельного господства власти в переформатированном ей социальном пространстве, которое возможно лишь в случае масштабной и непоправимой деградации связующих культурных идеалов, закономерно провоцирующей у индивидов «глубокое чувство онтологической незащищенности» [6, p. 163].

Итак, государственная власть в постапокалиптическом будущем, окончательно обесценив поколение «отцов», устанавливает непосредственную тоталитарную связь между собой и поколением «сыновей». Таким образом обеспечивается прямая трансляция отчужденных институциональных установок, отражающих практически ничем не ограниченные управленческие амбиции действующей власти. Подобная парадигма социальной коммуникации позволяет все более минимизировать содержательное действие опыта старших поколений на молодёжь. При этом ключевой управленческой задачей такой манипуляции становится формирование поколения, у которого живой опыт социокультурного взаимодействия и спектр его эмоциональных переживаний обречены на неуклонную деградацию на фоне агрессивно вытесняющих их институциональноформализованных моделей коммуникации. Стратегическая цель такой экстремальной социализации заключается в искусственном конструировании личностей и социальных групп с наперед заданными, а главное - предсказуемыми и безопасными реакциями на любые властные раздражители. 
Налицо биополитическая попытка властного замещения сложных комплексов индивидуальных познавательных реакций человека лояльными моделями функциональноролевой коммуникации. С психоаналитической точки зрения подобные процессы более всего напоминают воцарение «Сверх-Я», в котором отождествились как, собственно, сознание человека, так и его бессознательное в рамках институциональных «правил игры». А поскольку поколение «отцов» уже не является живым примером осознания и преодоления внутренних конфликтов, то подавляющее большинство индивидов на протяжении всей своей жизни наглядно демонстрирует примеры «обывательского мировоззрения, составленного из субъективных мнений, стереотипов корпоративных и территориальных идеологем» [7, с. 429]. Совершенно не удивительно, что, руководствуясь такими установками, они начинают все более идентифицировать себя только лишь с заранее предсказуемыми и ожидаемыми реакциями на любые властные манипуляции. По крайней мере, в процессе социального конструирования власти молодёжь воспроизводится уже только как поколение с заданными параметрами социальной коммуникации.

Однако на самом деле постапокалиптические общества будущего, изображаемые в голливудских франшизах (типичным примером которых и выступает трилогия о «Дивергенте»*), лишь отчасти соответствуют ожиданиям паноптической, по определению М. Фуко, власти и выступают иллюстрациями закономерного набора реакций «на меняющиеся исторические условия» [8, p. 123]. Демонстрируемая зрителям всего мира Америка будущего, которая жестоко разорена войной, - это строго регламентированное геополитическое пространство, искусственно составленное из социальных групп, принудительно разделенных по принципу их функциональной ценности для общества. Структура этого общества представлена пятью фракциями: «Эрудиция», «Бесстрашие», «Дружелюбие», «Отречение» и «Искренность» (рисунок), каждая из которых выполняет строго определенную и закрепленную за ее членами социальную миссию: «у каждой фракции есть свои идеологии, хотя они и уходят корнями от одних и тех же отцовоснователей» $[9$, p. 30].

С одной стороны, весьма показательно, что даже в названиях фракций воспроизводятся наиболее значимые для государства добродетели, поколенческое воспроизводство которых позволяет сформировать устойчивую иллюзию высокой моральности подобного социального пространства. С другой стороны, нарочитая фиксация моральных добродетелей в названиях фракций имеет исключительно формальный, демонстративный характер, и по сути является средством институционального вытеснения и сокрытия жестких, тоталитарных оснований существования этого постапокалиптического общества, в котором именно лжи был изначально придан статус истины. Для подготовленного исследователя-гуманитария такая ситуация недвусмысленно указывает на то, что «абсолютные истины трескаются, чтобы позиционировать неопределенность как философскую основу постмодерна» [10, р. 341]. Такая морализаторская бравада власти изначально направлена на принудительное укоренение среди подвластного населения безопасных иллюзий, представляющих «не просто <..> достоверную репрезентацию реальности, а $<\ldots>$ реальность саму по себе» $[11$, с. 84$]$, в рамках которой подвластное население убеждено в исключительной социальной сущности государства, его гуманистических и традиционалистских установок.

\footnotetext{
* «Дивергент» (англ. - Divergent, реж. Н. Бёргер, Summit Entertainment, 139 мин, США, 2014); «Дивергент, глава 2: Инсургент» (англ. - The Divergent Series: Insurgent, реж. Р. Швентке, Summit Entertainment, 119 мин, США, 2015); «Дивергент, глава 3: За стеной» (англ. - The Divergent Series: Allegiant, paнеe - The Divergent Series: Allegiant - Part 1, реж. Р. Швентке, Summit Entertainment, 110 мин, США, 2016).
} 


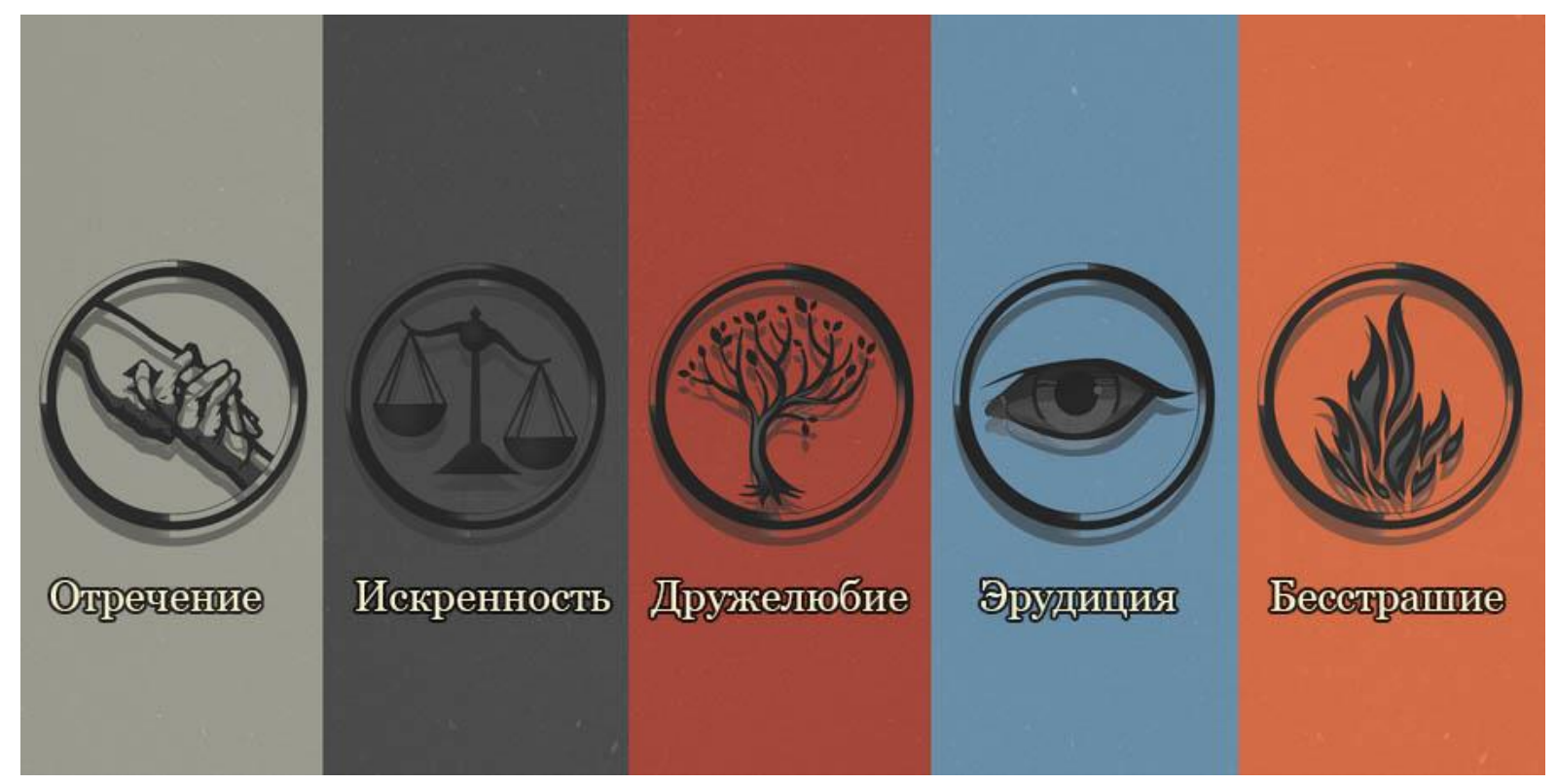

Рисунок. Символы пяти фракций города Чикаго

Figure. Symbols of the five factions of the city of Chicago

Кроме того, моральный контекст подобной дифференциации демонстративно указывает на исключительную ориентацию этого постапокалиптического общества на индивидуальный выбор каждым его членом своей жизненной траектории, смена которой в процессе всей дальнейшей биографии не допускается ни в коем случае, под угрозой фатального «выпадения» отступника из всей системы фракций, а значит, и из общества как такового. Формальное наличие свободы выбора сопровождается целым ворохом ограничений и правил, нарушение которых делает любого гражданина пожизненным «межфракционным» изгоем. Власть Америки будущего утверждает, что фракции формируются исключительно на основе свободного волеизъявления каждого и с учетом предварительно протестированных способностей потенциальных кандидатов с использованием самых передовых научных технологий. Однако торжественная и публичная церемония выбора фракций слишком уж напоминает процесс инициации с имитацией жертвоприношения кандидата и его публичной клятвы на крови в верности будущей фракции.

Беспристрастное биохимическое тестирование, которое проводится с каждым кандидатом, призвано определить и зафиксировать его наклонности посредством создания крайне небезопасных галлюцинаций, та или иная реакция на которые фактически и предопределяет дальнейшую фракционную судьбу каждого юноши или девушки. При этом, в полном соответствии с демократическими традициями бывших США, окончательный выбор все же остается за каждым отдельно взятым кандидатом и он вправе в последний момент на глазах у всех изменить свою судьбу, навсегда перейдя из одной фракции в другую. По идее, такая система, придуманная когда-то фракцией «Эрудитов», позволяет сформировать крайне консервативную, но гармоничную и предсказуемую социальную среду, где каждый человек пожизненно работает в соответствии со своими внутренними предрасположенностями, реализуя их на пользу себе и всему обществу. Действительно, «Эрудиты» изначально и, казалось бы, вполне обоснованно исходили из посылок, в рамках которых каждый человек представляет собой определенный набор качеств, который востребован, а потому целенаправленно формируется и поощряется государством. В этой модели социализации чётко соотнесены ведущие со- 
циальные приоритеты и передающиеся по наследству индивидуальные наклонности, которым искусственно придается исключительная социально значимая форма.

Однако заданная схема оказывается практически нежизнеспособной в случаях, когда молодые граждане в ходе тестирования внезапно начинают демонстрировать наличие сразу нескольких, казалось бы, взаимоисключающих наклонностей и способностей. Таких индивидов называют «дивергентами», демонстративно подчеркивая их отклоняющееся поведение, которое на основе имеющихся у них «сверхспособностей» сразу же выводит их за грань допустимого социального порядка. Соответственно, такие люди становятся для власти и общества намного более опасными, чем даже внефракционные «изгои», поскольку они уже не могут адекватно и неконфликтно встраиваться в сложившуюся столетиями систему фракций, чем создают смятение в умах и чувствах других людей, представляя реальную угрозу дальнейшего «безоблачного» функционирования хорошо отлаженного фракционно-государственного механизма. Нет сомнения, что именно «дивергенты» выступают «темными лошадками» для всей системы фракций, потому что наглядно демонстрируют наличие принципиально неконтролируемых властью способностей, которые и становятся главным социально дестабилизирующим фактором.

Фракционная система изначально отталкивалась от представлений об исключительной ангажированности природы человека в соответствии с запросами внешней среды, что создавало условия стабильного функционирования всего институционального пространства этого постапокалиптического общества, для которого «дисперсия ценностей, по существу, становится нормой» [12, с. 50]. Существование показной, демократически обставленной «Церемонии выбора» позволяет придать застойной, по сути социально-консервирующей системе фракций, иллюзию коллективного динамизма, который фиксируется на уровне общественного мнения как знак устойчивого и неуклонного прогресса всего общества. Следует оговориться, что традиционная институциональная среда государства, основанного на кланово-профессиональном или территориальном принципе, как правило, склонна проявлять себя крайне однообразно: она тщательно воспроизводит только уже надежно апробированные в поколениях стандартные наборы действий и коммуникативных схем, неуклонное исполнение которых неизбежно гарантирует обществу ту или иную степень стагнации. Поэтому реформы, революции, восстания и войны всегда выступают исторически «обкатанными» способами пересобирания общества по новым институциональным схемам.

Однако парадокс состоит в том, что при любых социальных трансформациях (которые могут включать «в себя варианты от преодоления определенных биологических ограничений до создания и расширения нового глобального разума и углубления человеческого сознания» [13, с. 669]) системообразующие институциональные содержания не изменяются в принципе, поскольку именно в них и концентрируются наиболее эффективные модели управления. Отсюда становится понятным поистине маниакальный по своему упорству запрос американской власти эпохи постапокалипсиса на создание абсолютно «прозрачной» и предсказуемой социальной среды, которая должна быть максимально отзывчивой к любым управленческим решениям. Как раз потому формирование подобной «отзывчивости» со стороны индивидов и социальных групп становится основной задачей государственной власти. В то же время появление «дивергентов» создает реальные угрозы социальной стабильности, поскольку исподволь провоцирует уже однажды определившихся в своей фракционной принадлежности молодых людей к «опасным» сомнениям, способным в перспективе «раскачать» и все остальное общество. 
Соответственно, в этих условиях основной задачей тоталитарной власти является недопущение возникновения «разлагающих» сомнений, в перспективе чреватых разрушением всего социального организма. Поэтому основным средством поддержания социальной стабильности становится принудительное и повальное тестирование населения фракций с целью выявления и физического устранения опасных дивергентов, умеющих чуть больше и видящих чуть дальше, нежели это пожизненно предписано фракционной кармой. В итоге члены фракции «Эрудитов» с параноидальной педантичностью начинают выискивать дивергентов, опираясь на негласный союз с боевиками из фракции «Бесстрашия», которая, по сути, превращается в главный карательнополицейский орган всей государственной системы. Дивергенты становятся основным камнем преткновения общества и власти, угрозой существования всей системы фракций. С точки зрения господствующей фракции «Эрудитов», главная опасность дивергентов состоит в угрозе дестабилизации общества, что чревато потерей их главенствующей роли в системе социального управления.

Кроме того, дивергенты становятся и основными носителями физических уязвимостей всей Государственной Системы, теми лакунами, сквозь которые незыблемая ещё недавно власть может легко улетучиться и полностью раствориться в хаосе межфракционной коммуникации по поводу вновь открывающихся возможностей жизненного выбора, не обрекающих каждого человека на пожизненное территориальное и функциональное рабство. Со стороны общества дивергенты воплощают потенциальную опасность утраты сложившихся форм удовлетворения физических потребностей, которые, правда, понимаются исключительно как духовно-нравственные и даже социоформирующие. Подобные повсеместно распространённые оценки существуют в форме стереотипов, в которых зафиксирован добровольный отказ людей от возможности самореализации ради гарантированного куска хлеба для себя и своих детей. Поэтому дивергенты практически со всех возможных точек зрения оцениваются как общесоциальные символы страха, который предательски и стремительно «врывается в <..> повседневность, делая невозможным выйти невредимым из этого опыта» [14, p. 230]. Эти символы подобны библейским вестникам беды и вселенского хаоса, грозящего навсегда унести с собой то немногое, что люди смогли сберечь в постапокалиптическом мире.

Как раз с такими парадоксальными противоречиями вплотную столкнулась и главная героиня франшизы Трис (Беатрис) Прайор, которую родители с детства готовили к жертвенному и бескорыстному служению людям во фракции «Отречение». Случайно обнаруженные в ходе биохимического теста абсолютные дивергентные способности девушки первоначально сильно испугали ее саму, поскольку она была практически не готова всерьез посмотреть на себя и свои способности с каких-то других, внефракционных позиций, хотя долгое время бессознательно ощущала свою моральнофизиологическую нетождественность поведенческим идеалам собственной фракции. Более того, главный жизненный выбор, в итоге приведший Трис в диаметрально противоположную по стилю мысли и действия фракцию «Бесстрашие», однозначно указывал на ее изначальное неосознаваемое стремление к разрушению всей отжившей системы социальных связей в этом искусственно созданном постапокалиптическом обществе.

Парадоксально, но такое интуитивное предощущение Трис со временем превращается в осознанное убеждение, что делает вполне понятными ее новые контакты с инсургентами, которые превратили идею уничтожения фракционного деления в свою воинствующую идеологию. Показательно, что «Эрудиты», как, впрочем, и члены других фракций, обнаруживая в своём составе дивергентов, создают условия для их остракиз- 
ма, тогда как идея физического уничтожения оппонентов для них является вторичной. А это значит, что деление постапокалиптического общества франшизы на фракции и инсургентов является одной из ключевых управленческих стратегий тоталитарной власти, оправдывающей как само свое существование, так и жестокие методы руководства. Удивительно, что сами инсургенты не изымаются властью из общественного организма, но являются его необходимой, «системной» составляющей. А их протестные, повстанческие, откровенно криминальные настроения и действия выступают необходимой социальной функцией нового постапокалиптического общества. Фактически как раз сообщество инсургентов и представляет единственную «системную оппозицию» всем имеющимся фракциям, позволяя тоталитарной власти и дальше укреплять свое могущество, ни сколько снижая, но всякий раз лишь наращивая силовое давление в отношении всего социального организма.

Именно такая оппозиция предоставляет власти возможность не только постоянно демонстрировать всему обществу «разделяемый членами группы прототип» [15, с. 30] и образ реального «врага», но и педалировать свою «адекватность» в силовом противостоянии ему. Показательно, что указанные социальные анклавы в истории цивилизации традиционно заключают между собой неписаный «общественный договор», согласно которому власть, в меру собственного понимания ситуации, «игнорирует» негативные процессы в инсургентных средах, а представители последних не только не стремятся уничтожить устоявшуюся государственную систему, но косвенным образом даже содействуют укреплению тоталитарного статус-кво. И только дивергенты, способности которых совершенно не укладываются в вековые коммуникационные традиции ни одной из вышеперечисленных социальных сред, представляют единственную социальную силу, способную не только осознать порочность системы фракций, но и предпринять реальные усилия по мобилизации общества для действенного противостояния ей.

Лишь третья (заключительная) часть франшизы дает зрителю возможность осознания всей уникальности общесоциальной миссии, возложенной на дивергентов полулегендарными «Отцами-основателями» всей системы фракций, живущими в таинственном месте под названием «Провиденс» и на протяжении последних двухсот лет тщательно, в буквальном смысле слова «паноптически», контролирующими эксперимент «фракционного бытия» постапокалиптических США на территории уничтоженного войной города Чикаго. Оказывается, секрет дивергентов состоял в том, что именно они в своих телах несли гены перволюдей, но в силу определенных исторических и техногенных катаклизмов их геномы были серьезно повреждены. И только Трис, ради которой, как выяснилось, и затевался весь этот эксперимент, оказалась тем искомым дивергентом, который обладал полностью неповреждённым геномом, что и дало право называть ее единственной «чистой» особью. Она фактически выступила реинкарнацией образа ницшеанского Сверхчеловека, полноценно воплощая в себе все «человеческое как сверхъестественное» [16, p. 105].

Работа над созданием технологии перерождения американцев, которой занималось «Бюро генетической экспертизы», по сути, приравнивает его усилия к разработкам нацистских ученых в концентрационных лагерях времен Второй мировой войны. Практика целенаправленного выведения «чистых» людей заново актуализирует многовековую, колониальную идею расовой дискриминации. Однако она же превращает такие эксперименты в государственно значимую социальную технологию биополитического толка, в логике которой «объект, подчиненный властному воздействию, просто перестает ощущать какое-либо давление, осознавая происходящее как нечто, что свойственно ему» $[17$, с. 75]. Фактически, постапокалиптический мир голливудской фран- 
шизы о «Дивергенте» оказывается искусственно сконструированной лабораторной площадкой, в пространстве которой оказались задействованы все основные историкоцивилизационные формы социальной коммуникации горизонтальной и вертикальной направленности. Так межличностные отношения в ней определяются функциональной целесообразностью фракционного деления, возвращая общество к «традиционному «деревенскому» укладу, где все знают обо всех, где нет ничего сокровенного, тайного» $[18$, c. 77$]$.

В то же время коммуникация между фракциями со временем абсолютно закономерно утрачивает равноправный характер, неуклонно вырождаясь в жесткую иерархическую, тоталитарную систему. Устойчивость такой социальной конструкции обеспечивается идеологической машиной властей постапокалиптического Чикаго, которые перманентно шантажируют руководство фракций и живущих в них людей необходимостью поддержания безопасности во имя сохранения всего существующего порядка и их статуса «аллигентов», по определению не имеющих «своей устойчивой субъективности» $[19$, с. 82], безраздельно преданных системе фракций и лояльных власти. Демонстрация людям «позитивных» результатов такой формы коммуникации осуществляется с помощью постоянно декларируемой угрозы возможной утраты привычной социальной среды и превращения части населения в преступников-инсургентов.

Показательно, что как раз наличие подобных сообществ во многом и позволяет властям поддерживать фракционно-разделенный Чикаго в постоянном «боевом» тонусе, который идеологически регулярно «приправляется» высокими идеалами самоотверженного служения каждого человека своей фракции, а значит, и всему обществу. Поэтому фракционная система является единственным примером высокоморальной коммуникации, в противоположность хищническим посягательствам коварных инсургентов. Однако венчает всю тоталитарную систему постапокалиптической Америки таинственное и могущественное «Бюро генетической экспертизы» - социальная группа, сам факт наличия которой придает ей сверхъестественный и сакральный смысл. Она фактически выведена за рамки общепринятой коммуникации, поскольку является метасоциальной силой, изначально устанавливающей и контролирующей правила социальной жизни. Таким образом, всеобщий контроль за постапокалиптической Америкой осуществляется посредством системы жестких социальных иерархий на уровне фракций, продуктивного союза власти и преступности, а также паноптического во всех смыслах этого слова, «теневого» элемента в лице «Бюро генетической экспертизы», полноценно представляющего сакрально-мистическую составляющую тоталитарного социального организма.

Однако ключевым двигателем такой жесткой тоталитарной системы все-таки оказывается идея дивергентных индивидов, которые непрерывно привносят в затхлое фракционное «болото» постапокалиптического Чикаго элементы непредсказуемости, управленческой нестабильности и творческого хаоса, фактически омолаживая «свежей кровью» этот стагнирующий биополитический социальный организм. Выступая закономерным результатом дивергентной эволюции, которая, по мнению ведущих ученыхэволюционистов, изначально базировалась на высокой адаптивности организмов в непрерывно изменяющемся мире, именно «отклоняющиеся» особи, при всей их генетической разносторонности, оказываются трагически неспособными полноценно встроиться как раз в тесную систему фракционных иерархий.

В то же время, как это ни парадоксально, и сами дивергенты, как «люди с восстановленной генетикой» [20], являются необычайно интересным и продуктивным материалом и для косной системы фракционной власти. Ведь ее основная задача состоит не 
в том, чтобы полностью истребить дивергентов, а в том, чтобы создать и апробировать биополитическую технологию максимальной «утилизации» их творческих способностей для придания видимости проектируемого порядка и управляемого развития всему социальному организму. Показательно, что с начала миллениума именно Голливуд твёрдо взял на себя роль визуальной рефлексии над наиболее актуальными трендами, которые формируются в новых социокультурных и геополитических условиях. Во многом благодаря актуальным техническим средствам и технологиям кинематограф сегодня смог превратиться в общепланетарную площадку, которая визуализирует и провозглашает наиболее острые противоречия современной цивилизации.

При этом наиболее разительным является явное доминирование ювенальной тематики, идеологически спроецированной на характер трагических предощущений будущего, столь характерных для начала XXI в. Поэтому ее практически безраздельное господство, особенно в постапокалиптическом и фантастическом жанрах массовой культуры, скорее указывает не на попытки выстроить конструктивные модели визуализации ближайшего или более отдалённого будущего, а на стремление во что бы то ни стало зафиксировать острейшие социально-политические противоречия сегодняшнего дня и попытаться отыскать наиболее адекватные сценарии включения подрастающего поколения в систему крошащихся на глазах традиционных культурных ценностей. Однако поскольку такие мотивы в интерпретации голливудских мастеров все чаще приобретают именно биополитический и постапокалиптический характер, то можно сделать совершенно логичный вывод о том, что перспективы гармонизации межпоколенческой коммуникации в большинстве существующих цивилизационных контекстов выглядят сегодня далеко не безоблачными, если не сказать откровенно трагическими.

\section{СПИСОК ЛИТЕРАТУРЫ}

1. Yüksel H. Cold war ideology: the Rocky 4 movie // Labour and society. - 2018. - V. 21. - Iss. 3. - P. $385-414$. URL: https://doi.org/10.1111/wusa.12351 (дата обращения 11.04.2021).

2. Кончаловский А.С. Низкие истины. - М.: Коллекция «Совершенно секретно», 2000. - 384 с.

3. Никулин Н. От братьев Люмьер до голливудских блокбастеров. Главное в истории кинематографа. М.: Эксмо, 2020. - 320 c.

4. Lawrence K. The horror of high school: formal vs informal learning in teen horror television // Teaching and Learning on Screen / Ed. by M. Readman. - London: Palgrave Macmillan, 2016. - P. 169-186. URL: https://doi.org/10.1057/978-1-137-57872-3_11 (дата обращения 11.04.2021).

5. Moreno E.T. A nightmare on Elm street: a cultural nightmare difficult to escape // Brumal. Revista de Investigación sobre lo Fantástico Investig ción so re lo antástico. - 2016. - V. IV. - № 2. - P. 227-246. URL: https://doi.org/10.5565/rev/brumal.220 (дата обращения 11.04.2021).

6. Jancovich M. «The theme of psychological destruction»: horror stars, the crisis of identity and 1940s horror // Horror Studies. - 2015. - № 6 (2). - P. 163-175. URL: https://doi.org/10.1386/host.6.2.163_1 (дата обращения 11.04.2021 г.).

7. Маленко С.А., Некита А.Г. Антропология пролетарской телесности: идеологическая стратегия потребления страданий и смерти в культурной традиции американского фильма ужасов // Вестник Томского государственного университета. Культурология и искусствоведение. - 2020. - № 39. C. 66-78. URL: https://doi.org/10.17223/22220836/39/7 (дата обращения 11.04.2021).

8. Hantke S. Writing horror in the eighties: an interview with Lisa Tuttle // Horror Studies. - 2019. - № 10 (1). P. 123-132. URL: https://doi.org/10.1386/host.10.1.123_1 (дата обращения 11.04.2021).

9. Wardana M.K., Roy S. Ideology and class division in Veronica Roth's Divergent // International Journal of Cultural and Art Studies. - 2019. - № 2 (1). - P. 30-37. URL: https://doi.org/10.32734/ijcas.v2i1.803 (дата обращения 11.04.2021).

10. Diamantino Valdés J.F.H.P. Lovecraft, Edición anotada // Ed. by L.S. Klinger. URL: https://doi.org/10.5565/rev/brumal.514 (дата обращения 11.04.2021).

11. Ульяновский А.В. Мифодизайн в рекламе. - СПб.: Изд-во Санкт-Петербургского университета, 2011. - 168 c. 
12. Кравченко С.А. Цифровые риски, метаморфозы и центробежные тенденции в молодежной среде // Социологические исследования. - 2019. - № 10. - C. 48-57. URL: http://socis.isras.ru/article/7851 (дата обращения 11.04.2021).

13. Platovnjak I., Tone Svetelj T. To live a life in Christ's way: the answer to a truncated view of transhumanism on human life // Bogoslovni vestnik. - 2019. - V. 79. - № 3. - P. 669-682. URL: https://doi.org/10.34291/BV2019/03/Platovnjak (дата обращения 11.04.2021).

14. De León Ramírez F.J. Ciertas estéticas del horror, ciertos horrores de la estética // Brumal. Revista de Investigación Sobre Lo Fantástico. - 2018. - № 6 (2). - P. 229-246. URL: https://doi.org/10.5565/rev/brumal.496 (дата обращения 11.04.2021).

15. Емелин В.А., Рассказова Е.И., Тхостов А.Ш. Единство и разнообразие процессов формирования идентичности личности // Вопросы философии. - 2018. - № 1. - С. 27-38.

16. Mendelyte A. Thomas Ligotti's bungalow universe and the transversal aesthetics of the weird // Horror Studies. - 2019. - № 10 (1). - P. 105-122. URL: http://dx.doi.org/10.1386/host.10.1.105_1 (дата обращения 11.04.2021).

17. Аласания К.Ю. Философская концепция биовласти: истоки и перспективы // Вестник Московского университета. Серия 7. Философия. - 2018. - № 4. - С. 70-77.

18. Лысак И.В. Сетевизация культуры: на пути к обществу взаимной прозрачности // Манускрипт. 2018. - № 4 (90). - C. 75-79. URL: https://cyberleninka.ru/article/n/setevizatsiya-kultury-na-puti-kobschestvu-vzaimnoy-prozrachnosti (дата обращения 11.04.2021).

19. Томильцева Д.А. Мораль в теории диспозитивов и проблема субъективности // Вестник московского университета. Серия 7. Философия. - 2016. - № 5. - C. 70-85. URL: https://cyberleninka.ru/article/n/moral-v-teorii-dispozitivov-i-problema-subektivnosti (дата обращения 17.04.2021).

20. Рот В. Эллигент. - М.: «Э», 2016. - 384 с.

Поступила 12.04.2021 г. 
UDC 316.621:316.648.43:327

\title{
JUVENILE PHOBIAS OF POST-APOCALYPTIC POWER: THE MORAL DEVOLUTION OF THE INDIVIDUAL IN THE MILLSTONES OF BIOPOLITICS
}

\author{
Sergey A. Malenko, \\ olenia@mail.ru \\ Andrey G. Nekita, \\ beresten@mail.ru \\ Yaroslav-the-Wise Novgorod State University, \\ 41, B. St. Petersburgskaya street, Veliky Novgorod, 173003, Russia
}

Sergey A. Malenko, Dr. Sc., professor, head of the Department of philosophy, cultural studies and sociology, Yaroslav-the-Wise Novgorod State University.

Andrey G. Nekita, Dr. Sc., professor, Yaroslav-the-Wise Novgorod State University.

Relevance. The anthropological crisis in which modern civilization is plunged sets new standards for the interpretation of contradictions between generations and dictates scenarios for their visualization. This conflict acquires a political and ideological sound, which urgently requires its humanitarian expertise, the formation of a body of recommendations to minimize the negative consequences. The aim of the research is to analyze the strategies for formation of a post-apocalyptic social space and the principles of deformation of intergenerational communication using the example of the Hollywood franchise about «Divergent». Methods. The authors rely on an interdisciplinary complex of semiotic, phenomenological and psychoanalytic methods, which allows a comprehensive analysis of the biopolitical and ideological strategies of postapocalyptic power. Results. The strengthening of the institutions of power of the future is carried out through the imposition of a totalitarian, hierarchical system, each level of which fulfills a prescribed moral mission, which makes it possible to rigidly give official and everyday functions to the highest sacred and anthropological meanings. The effectiveness of the existence of a factional system of a post-apocalyptic future is ensured by the creation of a rigid socialization mechanism designed to form and canonize standardized moral virtues. Functioning of such well-established mechanism is hindered by divergents, individuals who have all the factional abilities at the same time. Their universality undermines the stability of the dystopian society, which leads to the desire of the authorities to physically eliminate divergents from the social space. The state order is opposed by the non-systemic opposition of insurgents, deviants who seek to destroy factional determination. The demonstrative struggle of the factional society with the insurgents is its systemic function, which strengthens the positions of power, which is the natural result of shadow experiments on society. Findings. The use of occupational segregation technologies is becoming the leading biopolitical, communitarian strategy of post-apocalyptic, totalitarian power.

Key word: Post-apocalypse, divergent, insurgent, alligent, biopolitics.

\section{REFERENCES}

1. Yüksel H. Cold war ideology: the Rocky 4 movie. Labour and society, 2018, vol. 21, Iss. 3, pp. $385-414$. Available at: https://doi.org/10.1111/wusa.12351 (accessed 11 April 2021).

2. Konchalovskiy A.S. Nizkie istiny [Low truths]. Moscow, Kollektsiya «Sovershenno sekretno» Publ., 2000. 384 p.

3. Nikulin N. Ot bratev Lyumer do gollivudskikh blokbasterov. Glavnoe v istorii kinematografa [From the Lumiere brothers to Hollywood blockbusters. The main thing in the history of cinema]. Moscow, Eksmo Publ., 2020. 320 p. 
4. Lawrence K. The horror of high school: formal vs informal learning in teen horror television. Teaching and Learning on Screen. Ed. by M. Readman. London, Palgrave Macmillan, 2016. pp. 169-186. Available at: https://doi.org/10.1057/978-1-137-57872-3_11 (accessed 11 April 2021).

5. Moreno E.T. A nightmare on Elm Street: a cultural nightmare difficult to escape. Brumal. Revista de Investigación sobre lo Fantástico Investig ción so re lo antástico, 2016, vol. IV, no. 2, pp. 227-246. Available at: https://doi.org/10.5565/rev/brumal.220 (accessed 11 April 2021).

6. Jancovich M. «The theme of psychological destruction»: horror stars, the crisis of identity and 1940s horror. Horror Studies, 2015, no. 6 (2), pp. 163-175. Available at: https://doi.org/10.1386/host.6.2.163_1 (accessed 11 April 2021).

7. Malenko S.A., Nekita A.G. Antropologiya proletarskoy telesnosti: ideologicheskaya strategiya potrebleniya stradaniy i smerti v kulturnoy traditsii amerikanskogo filma uzhasov [Anthropology of proletarian physicality: the ideological strategy of consumption of suffering and death in the cultural traditions of the American horror film]. Vestnik Tomskogo gosudarstvennogo universiteta. Kulturologiya i iskusstvovedenie, 2020, no. 39, pp. 66-78. Available at: https://doi.org/10.17223/22220836/39/7 (accessed 11 April 2021).

8. Hantke S. Writing horror in the eighties: an interview with Lisa Tuttle. Horror Studies, 2019, no. 10 (1), pp. 123-132. Available at: https://doi.org/10.1386/host.10.1.123_1 (accessed 11 April 2021).

9. Wardana M.K., Roy S. Ideology and class division in Veronica Roth's Divergent. International Journal of Cultural and Art Studies, 2019, no. 2 (1), pp. 30-37. Available at: https://doi.org/10.32734/ijcas.v2i1.803 (accessed 11 April 2021).

10. Diamantino Valdés J.F.H.P. Lovecraft, Edición anotada. Ed. by L.S. Klinger. Available at: https://doi.org/10.5565/rev/brumal.514 (accessed 11 April 2021).

11. Ulyanovskiy A.V. Mifodizayn v reklame [Mythodesign in advertising]. St. Petersburg, St-Petersburg University Press, 2011. 168 p.

12. Kravchenko S.A. Tsifrovye riski, metamorfozy i tsentrobezhnye tendentsii v molodezhnoy srede [Digital risks, metamorphoses and centrifugal trends in the youth environment]. Sotsiologicheskie issledovaniya, 2019, no. 10, pp. 48-57. Available at: http://socis.isras.ru/article/7851 (accessed 11 April 2021).

13. Platovnjak I., Tone Svetelj T. To live a life in Christ's way: the answer to a truncated view of transhumanism on human life. Bogoslovni vestnik, 2019, vol. 79, no. 3, pp. 669-682. Available at: https://doi.org/10.34291/BV2019/03/Platovnjak (accessed 11 April 2021).

14. De León Ramírez F.J. Ciertas estéticas del horror, ciertos horrores de la estética. Brumal. Revista de Investigación Sobre Lo Fantástico, 2018, no. 6 (2), pp. 229-246. Available at: https://doi.org/10.5565/rev/brumal.496 (accessed 11 April 2021).

15. Emelin V.A., Rasskazova E.I., Tkhostov A.Sh. Edinstvo i raznoobrazie protsessov formirovaniya identichnosti lichnosti [Unity and diversity of the processes of personal identity formation]. Voprosy filosofii, 2018, no. 1, pp. 27-38.

16. Mendelyte A. Thomas Ligotti's bungalow universe and the transversal aesthetics of the weird. Horror Studies, 2019, no. 10 (1), pp. 105-122. Available at: http://dx.doi.org/10.1386/host.10.1.105_1 (accessed 11 April 2021).

17. Alasaniya K.Yu. Filosofskaya kontseptsiya biovlasti: istoki i perspektivy [The philosophical concept of biopower: origins and prospects]. Vestnik Moskovskogo universiteta. Seriya 7. Filosofiya, 2018, no. 4, pp. 70-77.

18. Lysak I.V. Setevizatsiya kultury: na puti k obshchestvu vzaimnoy prozrachnosti [Network culture: towards a society of mutual transparency]. Manuskript, 2018, no. 4 (90), pp. 75-79. Available at: https://cyberleninka.ru/article/n/setevizatsiya-kultury-na-puti-k-obschestvu-vzaimnoy-prozrachnosti (accessed 11 April 2021).

19. Tomiltseva D.A. Moral v teorii dispozitivov i problema subektivnosti [Morality in the theory of dispositives and the problem of subjectivity]. Vestnik moskovskogo universiteta. Seriya 7. Filosofiya, 2016, no. 5, pp. 70-85. Available at: https://cyberleninka.ru/article/n/moral-v-teorii-dispozitivov-i-problemasubektivnosti (accessed 11 April 2021).

20. Rot V. Elligent [Allegiant]. Moscow, «E» Publ., 2016. 384 p.

Received: 12 April 2021. 